\title{
An Integer Linear Programming for Container Stowage Problem
}

\author{
Feng Li, Chunhua Tian, Rongzeng Cao, and Wei Ding \\ IBM China Research Laboratory, \\ Beijing 100094, P.R. China \\ \{lfeng, chtian, caorongz, dingw $\} @ \mathrm{cn}$. ibm.com
}

\begin{abstract}
So far most stowage planning only consider the stowage of single type containers or do not consider the stability of the containership. Here a 0-1 linear programming model for this problem is proposed. The objective is to maximize space utilization while minimize the operation cost from upload and download of different types containers at each port of a multi-port journey, with vessel stability, industry regulations and customized rules as the constraints. Based on experiments by adopting branch \& cut algorithm from COIN-OR(Common Optimization Interface for Operations Research) to such model. Successively, a simulation system is developed to verify the feasibility and practicability of the model. By using the branch and cut algorithm of COIN-OR, the simulation system has shown that our model is efficient and robust.
\end{abstract}

Keywords: Container Stowage Planning, Integer Programming.

\section{Introduction}

Since the 1970s, containerization has increasingly facilitated the transportation of cargos. Nowdays over 60 percent deep-sea general cargo is transported in Containers, whereas some routes, especially between economically strong and stable countries, are containerized up to 100 percent [1]. There are lots of shipping companies competing around the world to provide profitable container transportation services. In order to increase the benefit of economy of scale, the size of containerships has enhanced. The increase in capacity has been typically from relatively small 350 Twenty Foot Equivalent Units (TEUs) to containerships with capacities of more than 8000 TEUs [2]. The increase of containership size contributes to incremental profits of shipping companies, it will cause a minus factor, enlarginging complexity and difficulty of the arrangement of containers. The arrangement of contaioners for a containership is usually called Container Stowage Problem (CSP).

CSP is complicated because of its combinatorial nature. In recent operations research and management science literatures, the mothods develped to sovle it can be grouped into five main classes: mathematical modeling, simulation based upon probability, decision support systems and heuristics. Among them, there are several objectives for the problem: optimizing available space and prevent 
damage, minimizing berthing time [3], minimizing total number of shifting of containers 4], maximizing containership's ultilization, and so on. Unfortunately those approaches have some commonalities with the problem and mainly devoted to the loading problem. The well-known mathematical model for CSP is integer linear programming [5]. Although those models can provide optimal solutions for CSP, they have incorporated too many simplification hypotheses, which have made them unsuitable for practical applications. The first simulation approach is completed by Shields [6]. In his work, a small number of stowage plans are randomly created to be evaluated and compared by simulation of the voyage and the best is selected. It is efficient in practice, it does not guarantee the optimality of the solutions, and it also takes a long computation time to find a reasonably good solution. Later, Saginaw and Perakis [7] and Shin and Nam 8] develop decision support systems that are based on the knowledge of a manager or an operator in charge of loading and unloading operations, Wilson et al. presented a realistic model, taking into account all technical restrictions in order to implement a commercial usable decision support system. They decomposed the CSP into two phases: strategic process and tactical process [9]. However, those decision support systems only show a solution of small sample problem and their efficiency from the practical viewpoint are not shown. The first heuristic for CSP is proposed by Martin et al. [10. They addressed CSP for the transtainer system, and developed a heuristic algorithm to solve it. Since then Todd and Sen implemented a genetic algorithm procedure with multiple criteria such as proximity in terms of container location on board and minimization of unloading-related re-handle, transverse moment and vertical moment [1], Haghani and Kaisar developed a heuristic algorithm for CSP with minimizing container handling cost, while keeping the containership's GM acceptable [12]. Dubrovsky et al. implemented a genetic algorithm-based heuristic for CSP [13]. These heuristics can produce complete and practical but rarely near-optimum solutions to the container stowage problem.

Considering those problems which are mentiioned above, an extend model for CSP will be proposed in this paper, which is used to find an optimal plan for stowing containers of different size into a containership on a multi-port journey, with a set of structural and operational restrictions. The objective is to maximize the containership utilization while minimize the operation cost from the container re-allocation. Such constraints and objective are firstly described in detail, then a basic 0-1 Linear Programming model is proposed. Successively, a simulation system was proposed to illustrate the efficiency of the model and compare it with random stowage strategy.

\section{Container Stowage Problem}

When solving CSP, of particular interest are the constraints related to the structure of the containership and the size of the hold and upper deck. We consider here two types of containerships, namely Ro-Ro (Roll on-Roll off), which load/unload containers through the ramps located either at the bow or the stern 


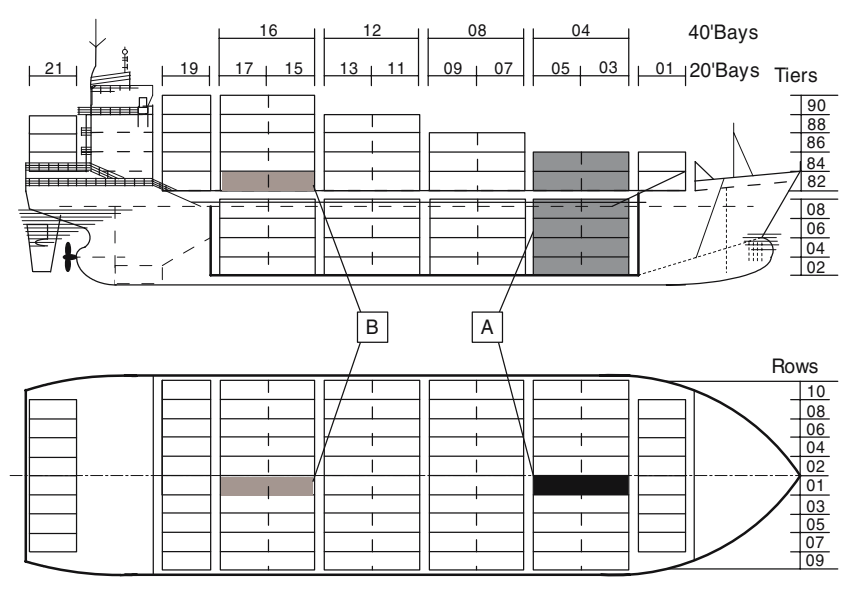

Fig. 1. Containership Structure

of the ship, and Lo-Lo (Lift on-Lift off), which load/unload containers from the top(by using cranes).

The basic structure of a containership and its cross section are shown in Figure 1. which are used to provide an idea of how container stowage take places. There are a given number of locations for placing containers, that can vary in size depending on the containership. The most common location is 8 feet in height, 8 feet in width and 20 feet in length. Each location is identified by three indies, each one consisting of two numbers given its position with respect to the three dimensions. In partice, each location is addressed by the following identifiers: (1) bay, that gives its position relative to the cross section of the containership (counted from bow to stern); (2) row, that gives its position relative to the vertical section of the corresponding bay (counted from the center to outside); (3) tier, that gives its position related to the horizontal section of the corresponding bay (counted from the bottom to the top of the containership). Thus a container will be located in a given bay, a given row and a given tier. In oder to describe CSP in detail, we propose the following notations.

Bay Index Sets: Let $I$ denote index set of bay set, $A$ and $B$ denote index sets of anterior part bay set and back part bay set, respectively, $E$ and $O$ denote index sets of even bay set and odd bay set, respectively, where $I=A \cup B, I=E \cup O$, $A \cap B=\emptyset$ and $E \cap O=\emptyset$.

Row Index Sets: Let $R_{i}$ denote index set of row set for the $i$ th bay, $L R_{i}$ and $R R_{i}$ denote index sets of left row set and right row set of the $i$ th bay, respectively. For example, the row set of the second bay for the containership shown in Figure 1is $\{09,07,05,03,01,02,04,06,08,10\}$, then $R_{2}=\{1,2, \cdots, 10\}$, $L R_{2}=\{1,2, \cdots, 5\}$ and $R R_{2}=\{6,7, \cdots, 10\}$.

Tier Index Sets: Let $T_{i j}$ denote index set of tier set for the $i$ th bay and the $j$ th row of $R_{i}$, let $U T_{i j}$ denote index set of upper tier set for the $i$ th bay and the 
$j$ th row of $R_{i}$ and let $B T_{i j}$ denote index set of below deck tier set of the $i$ th bay and the $j$ th row of $R_{i}$. Obviously, $U T_{i j} \cup B T_{i j}=T_{i j}$ and $U T_{i j} \cap B T_{i j}=\emptyset$

Port Set: Let $P$ denote the port set which are on the journey of the containership. Suppose $P=\{1,2, \cdots,|P|\}$.

Container Sets: Let $C_{p}(p=1,2, \cdots,|P|)$ denote the container set, which will be loaded on the containership at port $p$, and let $C=\cup_{p=1}^{|P|} C_{p}$. Let $w_{c}$ and $d_{c}$ denote the weight and destination port of container $c, \forall c \in C$, repectively. In this paper only two types of containers are considered, and let $F$ denote set of 40-feet container, $W$ denote set of 20 -feet container. Let $\hat{C}_{p}(p=1,2, \cdots,|P|)$ denote the set of containers which are loaded on port $i,(i=1,2, \cdots, p-1)$ and the order of those containers desitination port are greater than $p$. Obviously, when $p=1, \hat{C}_{p}=\emptyset$.

\subsection{Constraints}

Using these notations, some structural and operational restrictions can be described as follows. Because the number of the allocations provided by containership is finite, the maximum number of the containers which can be stowed on the containership is limitied. Thus at current port $p$,

$$
\begin{aligned}
\sum_{i \in I} \sum_{j \in R_{i}} \sum_{k \in T_{i j}} \sum_{c \in C_{p} \cup \hat{C}_{p}} x_{i j k c} \cdot s_{c} & \leq m_{t}, \\
\sum_{i \in E} \sum_{j \in R_{i}} \sum_{k \in T_{i j}} \sum_{c \in C_{p} \cup \hat{C}_{p}} x_{i j k c} & \leq m_{f} .
\end{aligned}
$$

where, $x_{i j k c}$ denote the variables of the optimizaiton, with the following specification:

$$
x_{i j k c}=\left\{\begin{array}{l}
1, \text { If the container } c \text { is stowed in location }\{i j k\}, \\
0, \text { otherwise. }
\end{array}\right.
$$

and location $\{i j k\}$ means the $i$ th bay, the $j$ th row of $R_{i}$ and the $k$ th tier of $T_{i j}$. $s_{c}$ denote the size of the container $c \in C$, and

$$
s_{c}=\left\{\begin{array}{l}
1, \text { If the size of container } c \text { is } 20 \text { foot, } \\
2, \text { If the size of container } c \text { is } 40 \text { foot. }
\end{array}\right.
$$

$m_{f}$ denote the maximum number of 40 -feet container which can be loaded on the ship. $m_{t}$ denote the maximum number of 20 -feet container which can be stowed on the ship. At the same time, each location of the containership can only have most one container and each container occupies one and only one location of the containership, therefore,

$$
\begin{aligned}
\sum_{i \in I} \sum_{j \in R_{i}} \sum_{k \in T_{i j}} x_{i j k c} \leq 1, \quad \forall c \in C_{p} \cup \hat{C}_{p}, \\
\sum_{c \in C_{p} \cup \hat{C}_{p}} x_{i j k c} \leq 1, \quad \forall i \in I, \forall j \in R_{i}, \forall k \in T_{i j} .
\end{aligned}
$$


The total weight of all containers which can be stowed on the containership can not exceed the maximum weight capacity of the containership.

$$
\sum_{i \in I} \sum_{j \in R_{i}} \sum_{k \in T_{i j}} \sum_{c \in C_{p} \cup \hat{C}_{p}} x_{i j k c} \cdot w_{c} \leq Q,
$$

where $Q$ denote the maximum weight capacity of the containership.

In practice, any 40-feet container can not be stowed in an odd bay and any 20feet container can not be stowed in an even bay; the stowage of 20-feet containers in those odd bays that are contiguous to even bays's location already chosen for stowing 40-feet container is unfeasible, and inversely; any 20-feet container can not be stowed on any 40-feet container; and any container can not be hangingly stowed. Then, we can get

$$
\begin{aligned}
& \sum_{c \in F \cap\left(C_{p} \cup \hat{C}_{p}\right)} x_{i j k c}=0, \quad \forall i \in O, j \in R_{i}, k \in T_{i j}, \\
& \sum_{c \in W \cap\left(C_{p} \cup \hat{C}_{p}\right)} x_{i j k c}=0, \quad \forall i \in E, j \in R_{i}, k \in T_{i j}, \\
& \sum_{c \in W \cap\left(C_{p} \cup \hat{C}_{p}\right)} x_{(i+1) j k c}+\sum_{c \in F \cap\left(C_{p} \cup \hat{C}_{p}\right)} x_{i j k c} \leq 1, \quad \forall i \in E, j \in R_{i}, k \in T_{i j}, \\
& \sum_{c \in W \cap\left(C_{p} \cup \hat{C}_{p}\right)} x_{(i-1) j k c}+\sum_{c \in F \cap\left(C_{p} \cup \hat{C}_{p}\right)} x_{i j k c} \leq 1, \quad \forall i \in E, j \in R_{i}, k \in T_{i j}, \\
& \sum_{c \in W \cap\left(C_{p} \cup \hat{C}_{p}\right)} x_{(i+1) j(k+1) c}+\sum_{c \in F \cap\left(C_{p} \cup \hat{C}_{p}\right)} x_{i j k c} \leq 1, \\
& \forall i \in E, j \in R_{i}, k \in U T_{i j},(k+1) \in U T_{(i+1) j} \text {, } \\
& \sum_{c \in W \cap\left(C_{p} \cup \hat{C}_{p}\right)} x_{(i-1) j(k+1) c}+\sum_{c \in F \cap\left(C_{p} \cup \hat{C}_{p}\right)} x_{i j k c} \leq 1, \\
& \forall i \in E, j \in R_{i}, k \in U T_{i j},(k+1) \in U T_{(i-1) j}, \\
& \sum_{c \in W \cap\left(C_{p} \cup \hat{C}_{p}\right)} x_{(i+1) j(k+1) c}+\sum_{c \in F \cap\left(C_{p} \cup \hat{C}_{p}\right)} x_{i j k c} \leq 1, \\
& \forall i \in E, j \in R_{i}, k \in B T_{i j},(k+1) \in B T_{(i+1) j}, \\
& \sum_{c \in W \cap\left(C_{p} \cup \hat{C}_{p}\right)} x_{(i-1) j(k+1) c}+\sum_{c \in F \cap\left(C_{p} \cup \hat{C}_{p}\right)} x_{i j k c} \leq 1, \\
& \forall i \in E, j \in R_{i}, k \in B T_{i j},(k+1) \in B T_{(i-1) j} \text {, } \\
& \sum_{c \in W \cap\left(C_{p} \cup \hat{C}_{p}\right)} x_{i j(k+1) c}-\sum_{c \in W \cap\left(C_{p} \cup \hat{C}_{p}\right)} x_{i j k c} \leq 0, \\
& \forall i \in O, j \in R_{i}, k \in U T_{i j}, k+1 \in U T_{i j}, \\
& \sum_{c \in W \cap\left(C_{p} \cup \hat{C}_{p}\right)} x_{i j(k+1) c}-\sum_{c \in W \cap\left(C_{p} \cup \hat{C}_{p}\right)} x_{i j k c} \leq 0, \\
& \forall i \in O, j \in R_{i}, k \in B T_{i j}, k+1 \in B T_{i j},
\end{aligned}
$$




$$
\begin{gathered}
\sum_{c \in F \cap\left(C_{p} \cup \hat{C}_{p}\right)} 2 x_{i j(k+1) c}-\sum_{c \in F \cap\left(C_{p} \cup \hat{C}_{p}\right)} 2 x_{i j k c}-\sum_{c \in W \cap\left(C_{p} \cup \hat{C}_{p}\right)} x_{(i-1) j k c}- \\
\sum_{c \in W \cap\left(C_{p} \cup \hat{C}_{p}\right)} x_{(i+1) j k c} \leq 0, \quad \forall i \in E, j \in R_{i}, k \in U T_{i j}, k+1 \in U T_{i j}, \\
\sum_{c \in F \cap\left(C_{p} \cup \hat{C}_{p}\right)} 2 x_{i j(k+1) c}-\sum_{c \in F \cap\left(C_{p} \cup \hat{C}_{p}\right)} 2 x_{i j k c}-\sum_{c \in W \cap\left(C_{p} \cup \hat{C}_{p}\right)} x_{(i-1) j k c}- \\
\sum_{c \in W \cap\left(C_{p} \cup \hat{C}_{p}\right)} x_{(i+1) j k c} \leq 0, \quad \forall i \in E, j \in R_{i}, k \in B T_{i j}, k+1 \in B T_{i j} .
\end{gathered}
$$

The stability of the ship is very important for the deep-sea container transprotation. Since the vertical, transverse and longitudinal distribution of a ship's weight, which is the most influencing factor for the ship's stability, is excessively unbalanced will lead it unstable, a bad stowage plan may result in the instability of the ship. To assure the stability of a containership, a stowage plan should satisfy several operational constraints. In this study the following three factors: metacentric height (GM), heel and trim are introduced to describe the vertical, transverse and longitudinal distribution of a ship's weight. For a ship to be stable, GM must be greater than the minimum allowable metacentric height, the heel should be narrow or at least to be smaller than a given small number, the trim is also close to zero or at least within certain prespecified limits for good performance of the ship. Hence a good stowage planning should make GM greater, heel and trim smaller to the extrem. Thus, the following constraints should be satisfied,

$$
\begin{aligned}
& w_{c} \cdot x_{i j k c}-w_{e} \cdot x_{i j k+1 e} \geq 0, \forall c, e \in C_{p} \cup \hat{C}_{p}, \forall i \in I, j \in R_{i}, k \in U T_{i j}, \\
& w_{c} \cdot x_{i j k c}-w_{e} \cdot x_{i j k+1 e} \geq 0, \forall c, e \in C_{p} \cup \hat{C}_{p}, \forall i \in I, j \in R_{i}, k \in B T_{i j}, \\
& -Q 1 \leq \sum_{i \in A} \sum_{j \in R_{i}} \sum_{k \in T_{i j}} \sum_{c \in C_{p} \cup \hat{C}_{p}} w_{c} \cdot x_{i j k c}-\sum_{i \in B} \sum_{j \in R_{i}} \sum_{k \in T_{i j}} \sum_{c \in C_{p} \cup \hat{C}_{p}} w_{c} \cdot x_{i j k c} \leq Q 2, \\
& -Q 3 \leq \sum_{i \in I} \sum_{j \in L R_{i}} \sum_{k \in T_{i j}} \sum_{c \in C_{p} \cup \hat{C}_{p}} w_{c} \cdot x_{i j k c}-\sum_{i \in I} \sum_{j \in R R_{i}} \sum_{k \in T_{i j}} \sum_{c \in C_{p} \cup \hat{C}_{p}} w_{c} \cdot x_{i j k c} \leq Q 3,
\end{aligned}
$$

where $Q 1, Q 2$ and $Q 3$ are given tolerance for stability of the ship.

In order to guarantee the containers in $\hat{C}_{p}$ still on the containership, when the containership begins to vessel to the other destination, the following equations should be satisfied,

$$
\sum_{i \in I} \sum_{j \in R_{i}} \sum_{k \in T_{i j}} x_{i j k c}=1, \quad \forall c \in \hat{C}_{p}
$$

\subsection{Objective Function}

In the container transportation industry, containerships make repeated tours of a sequences of ports according to their planned routes. At each port on a tour of 
a containership, containers are unloaded and additional containers destined for subsequent ports are loaded. Time duration required for loading and unloading depends on the arrangement of the cargo on board the ship, ie the stowage planning, which specifies where each container is loaded on the ship. Stowage plans, if not prepared well enough, may cause unnecessary handling time, time required for temporary unloading and re-loading of containers of gantry cranes at the ports. Consequently, port efficiency and ship utilization are largely affected by stowage plans.

In order to minimize the total rehandling of the containers on the ship. We propose the following objective functions,

$$
\min \sum_{p=2}^{|P|-1} \sum_{i \in I} \sum_{j \in R_{i}} \sum_{k \in T_{i j}}\left[\sum_{m \in T_{i j} ; m>k}\left(\sum_{c \in C_{p} \cup \hat{C}_{p}} d_{c} \cdot x_{i j m c}-\sum_{c \in C_{p} \cup \hat{C}_{p}} d_{c} \cdot x_{i j k c}\right)\right] .
$$

While considering the shifting number of the containers, we still want to improve the utilization of the containership. Thus we need another objective function, that is

$$
\max \sum_{i \in I} \sum_{j \in R_{i}} \sum_{k \in T_{i j}} \sum_{c \in C_{p} \cup \hat{C}_{p}} s_{c} \cdot x_{i j k c} .
$$

Definition 1. A vertical unit of the container means the container set with the same row and the absolute difference of their bay number is smaller than 1 .

Obviously the function value of (25) is not the real shifting number of the containers. In fact the shifting number of the containers can be calculate as follows,

$$
\sum_{p=2}^{|P|-1} \sum_{i \in I} \sum_{j \in R_{i}} \sum_{k \in T_{i j}} \sum_{m \in T_{i j} ; m>k} V_{i j m k p}
$$

where,

$$
V_{i j m k p}= \begin{cases}1, & \text { if } \sum_{c \in C_{p} \cup \hat{C}_{p}} d_{c} \cdot x_{i j m c}>\sum_{c \in C_{p} \cup \hat{C}_{p}} d_{c} \cdot x_{i j k c}, \\ 0, & \text { otherwise. }\end{cases}
$$

Theorem 1. If the container stowage problem is built up by objective function with (25]26) and constraints (124), it can minimize the container shifting number.

Proof. Obviously, we only need to prove that when (25) obtain its minimum, (27) can also get its minimum. Since only the containers in a vertical unit will result in the container shifting. Thus we only need to prove that for some vertical unit, the theorem is correct.

Without lose general, we suppose the Bay no of the vertical unit is $i^{\prime}$, Row no is $j^{\prime}$. When (25) gets its minimum we can get that,

$$
\sum_{c \in C_{p} \cup \hat{C}_{p}} d_{c} \cdot x_{i^{\prime} j^{\prime} m c} \leq \sum_{c \in C_{p} \cup \hat{C}_{p}} d_{c} \cdot x_{i^{\prime} j^{\prime} k c}, \text { if } m>k, m, k \in T_{i^{\prime} j^{\prime}} .
$$


Therefore, when (25) get its minimum, the shifting nubmer will be zero. Zero is the minimum of (27).

\section{$3 \quad$ Numerical Examples}

According to this integer programming container stowage planning model, we can generate an optimal container stowage strategy for the ocean shipping liners. Below a simulation system was proposed to illustrate it.

In order to verify the efficency of the integer model for the container stowage problem, we develop a simulation system. In this system, there are two stowage engine, the first one is our model, the second one is "random". Here "random" means we stowage the containers onto the containership randomly, it is said that for any container, we randomly generate a position with bay row and tie, if the position is available, then we stowage that container on it, otherwise we generate another position until the position is available. In order to display the result of those two stowage engine, a $3 \mathrm{~d}$ view of the containership is developed. The $3 \mathrm{~d}$ view of the containership is built up on a containership generator. By using this generator, any type of containership can be built. Besides stowage engine, $3 \mathrm{~d}$ view, and containership generator module of the system, there are data input, container generator, vessel operation calculation and report module in this simulation system. The function of data input is to input the data of routes(a sequences of ports) of the contianership. The container generator is to produce containers with different types, sizes and destination. The vessel operation calculation is to caluate the shifting number of the container at each port, the utilization of the vessel, and the weight balance of the veseel including the absolute weight difference between the front and rear, the absolute weight between the left part and the right part. The report module is show all of the calculation result and the statistics of the container on the vessel, such as how many container with the same destination.

In order to verify the efficiency of the model, a containership with 20 bays 10 rows and 10 ties is built up. We suppose that the maximum capacity of the containership is $800 \mathrm{TEU}$ and its maximum load capacity is $18,000 \mathrm{TON}$. For this vessel we build up a routes with 10 ports. At each port we randomly generate different types, different weight and different destination containers. Each time we generate all containers, then we vessel the containership, we load all of the containers from the first ports of the route, then unload the container for the second port and load the other containers for the coming ports, and so on. We have done the stowage process about 1000 times, and the stowage results are shown in Table 1 and Figures 25

Table 1 shows that, the shifting number, ultilization of the containership, and the weight balance difference of the vessel for the optimal stowage strategy are better than that of the random strategy. By using our model, the shifting number of the container handling has been cutten down to Zero. The irrationality of the ramdom stowage strategy will result in some containers can not be loaded on the vessel. Since the random stowage strategy don't consider the weigth balance 
Table 1. Compare Result for Optimal

\begin{tabular}{c|c|c|c|c}
\hline & \multicolumn{2}{|c|}{ Random } & \multicolumn{2}{c}{ Optimal } \\
\cline { 2 - 5 } & Mean & Variation & Mean & Variation \\
\hline Shifting Number & 1800 & 200 & 0 & 0 \\
\hline Utilization & $89 \%$ & 0.10 & $95 \%$ & 0.04 \\
\hline $\begin{array}{c}\text { Weight Balance } \\
\text { Difference (TON) }\end{array}$ & 50 & 10 & 8 & 2 \\
\hline
\end{tabular}

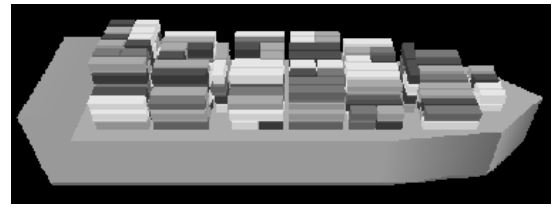

Fig. 2. 3d-View for Random Stowage Strategy(Up Deck)

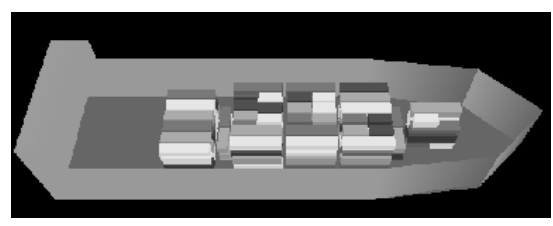

Fig. 3. 3d-View for Random Stowage Strategy(Down Deck)

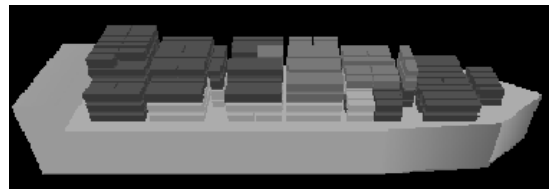

Fig. 4. 3d-View for Optimal Stowage Strategy(Up Deck)

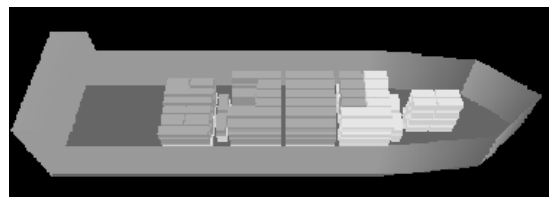

Fig. 5. 3d-View for Optimal Stowage Strategy(Down Deck)

of the vessel, it will lead the absolute weigth difference between the front and back of the vessel and the left and right part of the vessel bigger than that of the optimal stowage strategy. Thus the stability of the vessel has been improved by the optimal stowage strategy.

\section{Conclusion}

In this paper, an integer programming for the container stowage problem is proposed. It is suitable for multiple port and multimodel container transportation services. In this model, the container loading process and re-handling process are considered to minimize the container shifting number and maximize the utilization of the containership. At the same time several real rules of the ocean shipping industry and vessel stability are been concerned as constrains of the model. A simulation system is developed to verify the feasibility and practicability of the model. By using the branch and cut algorithm of COIN-OR, the simulation system has shown that our model is efficient and robust. 


\section{References}

1. Steenken, D., VoB, S., Stahlbock, R.: Container terminal operation and operations research: a classification and literature review. OR Spectrum 26, 3-49 (2004)

2. Methodologies for reducing truck turn time at marine container terminals. Research Report SWUT/05/167830-1

3. Atkins, W.H.: Modern marine terminal operations and management. Boyle, Oakland (1991)

4. Kang, J.G., Kim, Y.D.: Stowage planning in maritime container transportation. Journal of the Operational Research Society 53, 415-426 (2002)

5. Ambrosino, D., Sciomachen, A., Tanfani, E.: Stowing a containership: the master bay plan problem. Transportation Research Part A 38, 81-99 (2004)

6. Shields, J.J.: Container-ship stowage: a computer-aided preplanning system. Marine Technology 21, 370-383 (1984)

7. Saginaw, D.J., Perakis, A.N.: A decision support system for containership stowage planning. Marine Technology 26, 47-61 (1989)

8. Shin, J.Y., Nam, K.C.: Intelligent decision support system for containership autostowage planning. Journal of Korean Institue Port Research 9, 19-32 (1995)

9. Wilson, I.D., Roach, P.A., Ware, J.A.: Container stowage pre-planning: using search to genetrate solutions, a case study. Knowledge-Based Systems 14, 137$145(2001)$

10. Martin, J., Randhawa, S.U., McDowell, E.D.: Computerized container-ship load planning: A methodology and evaluation. Computers \& Industrial Engineering 9, 357-369 (1988)

11. Todd, D.S., Sen, P.: A multiple criteria genetic algorithm for containership loading. In: Proceedings of the Seventh International Conference on Genetic Algorithms, pp. 674-681 (1997)

12. Haghani, A., Kaisar, E.I.: A model for designing container loading plans for containerships. In: Annual Conference for Transportation Research Board (2001)

13. Dubrovsky, O., Levitin, G., Penn, M.: A genetic algorithm with a compact solution encoding for the container ship stowage problem. Journal of Heuristics 8, 585-599 (2002) 